\title{
Bridging the epilepsy treatment gap in low- and middle-income nations
}

Sir,

Epilepsy is a chronic disorder of the brain occurring among people from all age groups across the world. ${ }^{[1]}$ The disease has been acknowledged as a major global health concern owing to its high prevalence of 50 million and an incidence of 2.4 million each year. ${ }^{[2]}$ From the socioeconomic perspective epilepsy has been associated with fear, myths and misconceptions, social stigma and discrimination to the patient and their family members, significant impact on the quality of life, loss of disability-adjusted life years, premature and sudden deaths, loss of work productivity, financial burden on the health care delivery system, and violation of human rights (viz., restricted access to health and life insurance, difficulty in obtaining a driving license, no eligibility for specific occupations, etc.). ${ }^{[1-3]}$

Furthermore, in contrast to the estimates of annual new cases in high-income nations (viz., 30-50 people/0.1 million population), the incidence rates in middle- and low-income nations is almost double. ${ }^{[2]}$ This is predominantly because of the high prevalence of infections (such as malaria, neurocysticercosis, etc.), road traffic accidents, birth trauma; weak health infrastructure, including shortcomings in health staffs and logistics; and limited accessibility to the desired package of service, in the developing nations. ${ }^{[1,2]}$ In addition, it has been estimated that almost $80 \%$ of the people with epilepsy are from low- and middle-income nations, of which $75 \%$ cannot avail the desired treatment (epilepsy treatment gap) due to various constraints. ${ }^{[1,2]}$

However, owing to the fact that close to three-fourth of people with epilepsy usually respond to anti-epileptic drugs, the affordable cost of annual medications, and definitive possibility to diagnose/treat at the primary level of health care itself, without the use of sophisticated equipments, it is an alarming concern that almost $75 \%$ of diseased people are still devoid of the treatment in low-resource settings. ${ }^{[1-3]}$ There is an extensive need to improve public and professional awareness that epilepsy is a treatable brain disorder, enhance the level of acceptance with regard to epilepsy patients among the society, 
ascertain the needs of people with epilepsy at the grass-root level, integrating epilepsy control into local health systems, and motivate policy makers to respond to the varied demands of individuals suffering from epilepsy. ${ }^{[1,4]}$

A wide range of measures such as ensuring the availability of anti-epileptic drugs in all the health centers, organizing training sessions for the health professionals to diagnose and treat epilepsy, conducting periodic and extensive awareness campaign to negate the stigma associated with the disease, implementing preventive measures (such as prevention of head injury, adequate perinatal care, prompt medical attention to reduce the body temperature of a feverish child, elimination of infections which can precipitate epilepsy, etc.), and offering surgical options to those who respond poorly to the drugs, have been advocated.$^{[1,2,4]}$

To conclude, epilepsy being a major public health concern in low- and middle-income nations, and a preventable and treatable neurological disease through cost-effective drugs, it is high time that targeted measures are implemented to not only reduce the treatment gap but even improve the quality of life of patients and their family members.

\section{Financial support and sponsorship}

Nil.

\section{Conflicts of interest}

There are no conflicts of interest.

Saurabh RamBihariLal Shrivastava, Prateek Saurabh Shrivastava, Jegadeesh Ramasamy Department of Community Medicine, Shri Sathya Sai Medical College and Research Institute, Kancheepuram, Tamil Nadu, India
Address for correspondence: Dr. Saurabh RamBihariLal Shrivastava, $3^{\text {rd }}$ Floor, Department of Community Medicine, Shri Sathya Sai Medical College and Research Institute, Ammapettai Village, Thiruporur-Guduvancherry Main Road, Sembakkam Post, Kancheepuram - 603 108, Tamil Nadu, India. E-mail: drshrishri2008@gmail.com

\section{References}

1. World Health Organization. Mental health action plan 2013-2020. Geneva: WHO Press; 2013. p. 1-26.

2. World Health Organization. Epilepsy - Fact Sheet; 2016. Available from: http://www.who.int/mediacentre/factsheets/fs999/en/. [Last accessed on 2016 Feb 14].

3. Tomson T, Surges R, Delamont R, Haywood S, Hesdorffer DC. Who to target in sudden unexpected death in epilepsy prevention and how? Risk factors, biomarkers, and intervention study designs. Epilepsia 2016;57 Suppl 1:4-16.

4. Hesdorffer DC, Begley CE. Surveillance of epilepsy and prevention of epilepsy and its sequelae: Lessons from the Institute of Medicine report. Curr Opin Neurol 2013;26:168-73.

This is an open access article distributed under the terms of the Creative Commons Attribution-NonCommercial-ShareAlike 3.0 License, which allows others to remix, tweak, and build upon the work non-commercially, as long as the author is credited and the new creations are licensed under the identical terms.

\begin{tabular}{|l|l|}
\hline \multicolumn{2}{|c|}{ Access this article online } \\
\hline Quick Response Code: & Website: \\
\hline & www.ruralneuropractice.com \\
\cline { 2 - 3 } & \\
\hline
\end{tabular}

How to cite this article: Shrivastava SR, Shrivastava PS, Ramasamy J. Bridging the epilepsy treatment gap in low- and middle-income nations. J Neurosci Rural Pract 2016;7:475-6. 